Article

\title{
Preferring and Detecting Face Symmetry: Comparing Children and Adults Judging Human and Monkey Faces
}

\author{
Anthony C. Little ${ }^{1, *}$ and Jack A. F. Griffey ${ }^{2}$ \\ 1 Department of Psychology, University of Bath, Bath FK9 4LA, UK \\ 2 Department of Psychology, University of Stirling, Stirling FK9 4LA, UK; jackgriffey@hotmail.co.uk \\ * Correspondence: a.little@bath.ac.uk or dranthonylittle@gmail.com
}

Received: 14 October 2020; Accepted: 9 December 2020; Published: 19 December 2020

\begin{abstract}
Background: Visual symmetry is often found attractive. Symmetry may be preferred either due to a bias in the visual system or due to evolutionary selection pressures related to partner preference. Simple perceptual bias views predict that symmetry preferences should be similar across types of stimuli and unlikely to be related to factors such as age. Methods: The current study examined preferences for symmetry across age groups (pre-puberty vs post-puberty) and stimuli type (human face vs monkey face). Pairs of images manipulated for symmetry were presented and participants asked to choose the image they preferred. Participants repeated the task and were asked to detect symmetry. Results: Both age of observer and stimuli type were associated with symmetry preferences. Older observers had higher preferences for symmetry but preferred it most in human vs monkey stimuli. Across both age groups, symmetry preferences and detection abilities were weakly related. Conclusions: The study supports some ideas from an evolutionary advantage view of symmetry preference, whereby symmetry is expected be higher for potential partners (here human faces) and higher post-puberty when partner choice becomes more relevant. Such potentially motivational based preferences challenge perceptual bias explanations as a sole explanation for symmetry preferences but may occur alongside them.
\end{abstract}

Keywords: symmetry; asymmetry; face preference; detection; development

\section{Introduction}

Perceptual symmetry represents an orderly arrangement of parts of a stimulus (e.g., images, objects, or organisms), with stimuli having complete correspondence between the two halves of a central dividing line (bilaterally symmetric). Stimuli vary in symmetry, with higher asymmetry being greater deviation between the two halves. Symmetry has long been associated with aesthetic appeal and beauty in humans and has consequently generated much research in this context. For example, symmetry has been shown to be positively associated with preferences in abstract patterns see, e.g., $[1,2]$. Much research has also focused on salient biological stimuli, especially human preferences for symmetry in other human's faces [3-7].

Studies using a variety methods, such as measuring symmetry from real faces [3-7] or by artificially manipulating it in faces [8,9], have shown preferences for symmetry over asymmetry, although effect sizes are generally low. Research has typically made use of 2D images, which are not how faces are typically encountered. Symmetry preferences have also been found in more realistic stimuli such as in manipulations of symmetry in 3D face images [10] and in the symmetry of facial movements from video [11]. Some studies, however, do not show preferences for symmetry. Despite some studies showing no significant impact of symmetry, e.g., [12-15] and when using more sophisticated 
manipulations [14,15], overall, reviews suggest symmetry is an attractive trait in faces [16], although the small effect sizes suggest the strength of the impact of symmetry on attraction is relatively weak [16].

While the impact of symmetry on preferences may be small, it does appear to be a general aspect of human aesthetics. For example, studies on faces have found preferences for symmetry across different cultures indicating cross-cultural agreement on the attractiveness of symmetry $[17,18]$. Symmetry is not just appreciated by humans; symmetry in mate choice is preferred in many animal species [19]. For example, in the domain of faces, macaque monkeys will gaze longer at symmetrical face images of conspecifics than at asymmetrical versions [20]. Moreover, cross-cultural and cross-species agreement on the attractiveness of symmetry is suggestive that symmetry preferences may be driven by some universal mechanism or mechanisms shared across individuals.

Two main theories have been proposed to account for potential widespread symmetry preferences, a perceptual bias view and an evolutionary advantage view. The perceptual bias view proposes that symmetry preferences arise from biases in perceptual systems such that symmetrical stimuli are more easily processed and then preferred [21]. Simple perceptual bias views suggest symmetry is preferred because there is redundancy of information in symmetric stimuli because information is identical bilaterally making such images easier to process. Other simple views suggest preferences are due to the same information being presented to both hemispheres of the brain from the left and right visual field and so more easily processed [22-24]. Preferences for symmetry seen for a wide range of stimuli, such as everyday objects [25] and decorative art [26], are consistent with such a simple perceptual bias view.

A more complex perceptual bias view for symmetry preference is linked to processing of visual stimuli and cognitive theories about mental prototypes. In this view, symmetry is preferred because the average of a category of stimuli are generally symmetric when asymmetry is random. Similarity to an internal prototype for that class of stimuli causes symmetric stimuli to be attractive because they appear familiar or are easier to process $[21,27]$. Symmetry preferences can then be generated with experience of asymmetric stimuli, which results in a symmetric prototype. Models and experiments have shown that this can arise naturally [27-30].

In contrast to perceptual bias views, in which preferences for symmetry are an epiphenomenon of processing, the evolutionary advantage view suggests an evolutionary adaptation to identify high-quality mates may generate symmetry preferences, e.g., [21,31,32]. Symmetry has been linked to heritable fitness and may offer others a visual cue of how well that organism can develop a symmetric body plan under genetic and environmental stress. Symmetry may then be a cue to both phenotypic and genotypic quality (e.g., the ability to resist disease, [19]). This relationship is not reviewed here, but even a weak link between symmetry and quality would lead to a selection pressure for preference for symmetric partners. Studies have found results that are consistent with this view by demonstrating that symmetry preferences vary in predictable ways. For example, preferences for symmetry are strongest for opposite-sex faces, faces most relevant to mate choice [33-35]. Symmetry also appears to be more strongly preferred when individuals are primed with disease concern. Exposure to pathogen cues increases preferences for symmetry over asymmetry in faces [36,37], which is suggestive that symmetry is partly found attractive because it indicates something about the health of the person being judged. This variation also challenges perceptual bias views, which do not predict variation in the same way.

There are several other studies which show variation in symmetry preferences, which are also problematic for perceptual views. Perceptual bias views would generally assume that the type of stimuli should not matter for symmetry preferences. Studies [36,38-41] show, however, that stimuli type makes a difference. For example, symmetry is preferred more in human faces than in abstract face-like stimuli [36] and more in human faces than in either monkey faces or abstract art images [39]. The notion that humans may have specific criteria for attractiveness that apply more to human faces has also received support from studies examining the general attractiveness of faces across species. Asking humans to rate non-human primate faces from three different primate groups for attractiveness 
has shown that some cues used by humans to judge attractiveness in humans also apply to non-human primates, but only in Catarrhines, the primate group most similar to humans [40]. Comparing human and macaque monkey visual preferences, it has been shown that humans show visual preferences for human faces rated as attractive by humans while macaques show visual preferences for macaque faces rated as attractive by humans [41]. Such preferences appear mediated partly by species as humans did not show visual preferences for attractive macaque faces and macaques did not show visual preferences for attractive human faces [41].

The impact of experience and motivational factors also challenges the notion that symmetry is universally preferred in a similar way as predicted by simple perceptual bias views. In a study comparing art experts (artists and art historians) to non-experts, art experts rated asymmetry higher for beauty and preferred it to symmetry, in contrast to non-experts who preferred symmetry [42]. Comparing implicit and explicit measures of symmetry preference for art, observers with more expertise had similar implicit preferences for symmetry over asymmetry to non-experts but experts had explicitly stronger preferences for asymmetry than non-experts [43]. Together, these results suggest some universality to symmetry preferences at the implicit level, but that for explicit preference, and perhaps then choice, some top-down processing impacts symmetry preferences. This processing is likely experience-linked and may also reflect differing motivations in appraisal between experts and non-experts. In terms of face symmetry preferences, everyone may be considered a face expert, but there are factors that could affect the motivation to judge faces based on different criteria in a similar way to experts and non-experts. For example, puberty is a time when mate choice becomes a more relevant motivating factor in attractiveness decisions. Indeed, it has been shown, in women, that preferences for masculine male faces is higher post-puberty than pre-puberty [44], potentially reflecting a shift to prefer more mate choice relevant traits. One prediction of the evolutionary advantage view, then, is that symmetry would be more preferred in human faces post-puberty.

The purpose of the current study was to further examine domain specific effects and experience/puberty effects by testing pre-puberty and post-puberty groups on preferences for symmetry in human versus monkey faces. Simple perceptual bias views would predict similar preferences across stimuli and groups, whereas an evolutionary advantage view would predict greater symmetry preferences in the older post-puberty group and in human versus monkey faces. Some aspects of symmetry preference may be mediated by asymmetry detection abilities [10], and so detection tests were also administered.

\section{Materials and Methods}

\subsection{Participants}

Adults: Participants were 63 men (aged 16-57, mean $=32.3, \mathrm{SD}=10.5$ ). Participants were volunteers who were recruited via a dedicated research website.

Children: Participants were 45 boys (aged $8-11$, mean $=9.1, S D=1.0$ ). Participants were volunteers who were recruited during a visit to the university as part of a Cub Scout meeting.

All participants were male as the sample of children was an opportunity sample and an all-male group and the adult sample was recruited as all male to match.

\subsection{Asymmetric/Symmetric Human and Monkey Faces}

For human stimuli, photographs of white individuals (aged between 18 and 25) without spectacles randomly selected from a pre-existing database. In the photographs, individuals posed with a neutral expression under standardised lighting conditions. For macaque monkey images, neutral front-on images were extracted from video recordings with variable lighting conditions see [45]. Human and monkey images were aligned on inter-pupillary distance to equate size.

To measure preferences for symmetry, pairs of composite images, one symmetric and one asymmetric were used (see Figure 1). Composite images were made by combining 5 images of different 
individuals which were used as base faces for transforming. We created 10 human male, 10 human female, 10 monkey male, and 10 monkey female composite images by creating an average image made from 5 randomly assigned individual facial images [46-48]. These base faces were made symmetrical in shape and then a transform applied. To equate the asymmetry/symmetry difference across face type, we applied a unique transform based on the difference between one human face image and its symmetrical counterpart. For example, face 1 from each face type had the same transform applied based on the difference between an individual human face's symmetric and asymmetric version [39]. Images were masked around the outline of the face. The symmetric/asymmetric images used in the test were 5 human female pairs, 5 monkey female pairs, 5 human male pairs, and 5 monkey male pairs.

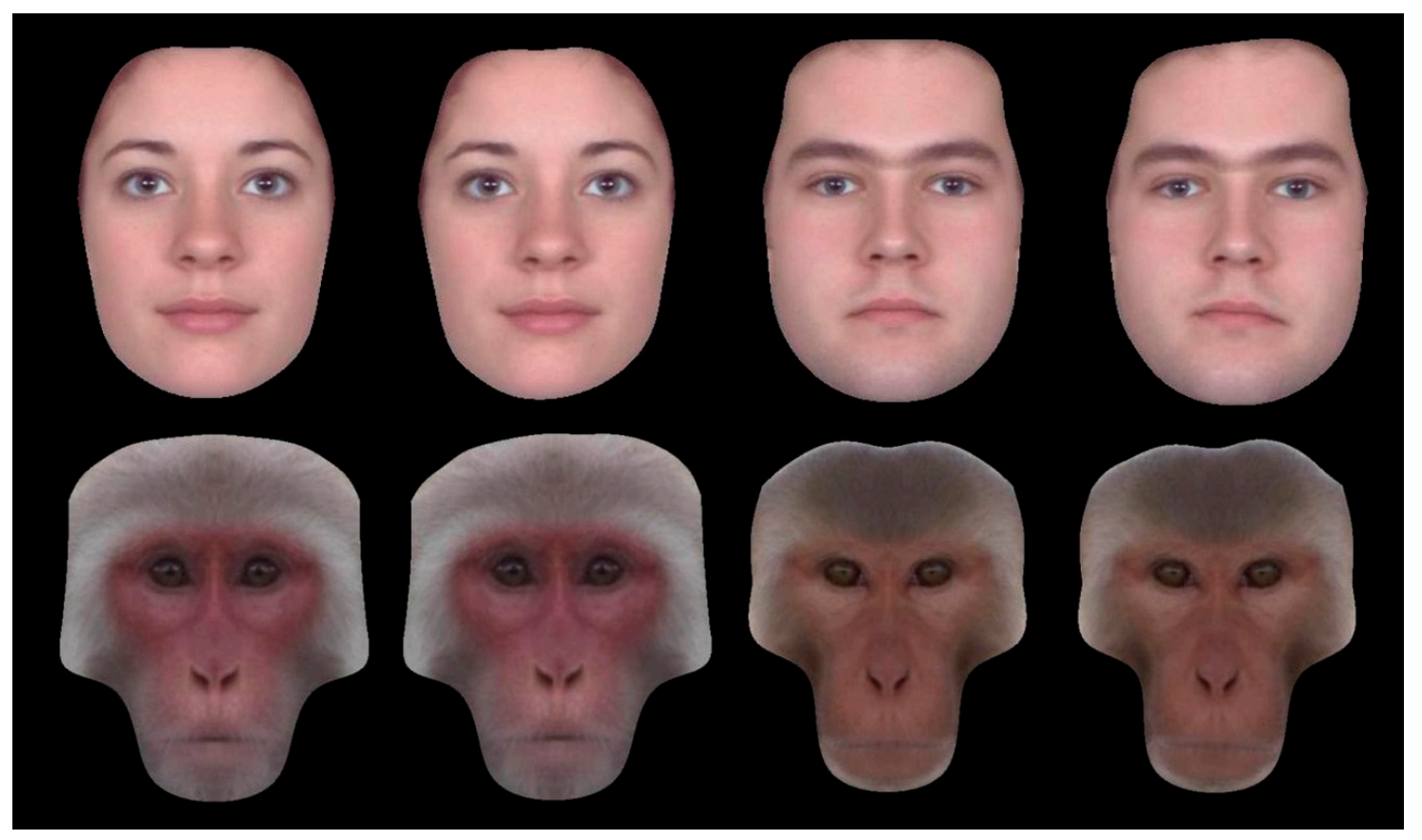

Figure 1. Examples of symmetric (left image of pair) and asymmetric (right image of pair) images for female humans (top left), male humans (top right), female monkeys (bottom left), and male monkeys (bottom right).

\subsection{Procedure}

Adults: Participants were administered the test online, which first asked for the participants age and sex. This was followed by the main test. The instructions were: "In this study you will see human and monkey faces and asked to choose between pairs of images to select the image you find more pleasant". The preference test consisted of paired images presented side by side, with left/right randomised. Selecting an image started the next trial. Images remained on screen until participants selected an image. Image pair order was also randomised. After the preference test, the same test was repeated for detection with the question changing to: "In the next part of this study, please select the image out of the pair which appears most symmetrical. Symmetrical images appear the same in both halves.".

Children: Participants were administered the test in person and completed using a printed answer sheet which asked age and sex. The sheet then had blank spaces for answers to each trial of the test. This was followed by the main test. The instructions were: "In this study you will see human and monkey faces and asked to choose between pairs of images to select the image you find more pleasant". The preference test consisted of paired images presented side by side via PowerPoint to the group. The slides were presented until it was confirmed that everyone in the group had made their choice. Participants were allocated to one of groups $(\mathrm{N}=12,12,11,10)$ to enable counterbalancing. All pairs 
were presented in a random order, and with symmetry left/right randomised. Group 1 saw the original order and original left/right, group 2 saw the original order with reversed left/right, group 3 saw the reversed order and original left/right, and group 4 saw the reversed order and reversed left/right. After the preference test, the same test was repeated for detection with the question changing to: "In the next part of this study, please select the image out of the pair which appears most symmetrical. Symmetrical images appear the same in both halves.".

\section{Results}

Preference and detection scores were calculated by taking the mean of trials in which symmetric images were selected $(0=$ asymmetric images selected, $1=$ symmetric images selected $)$ for each face type (human male, human female, macaque male, and macaque female). This number was multiplied by 100 to create a percent preference for symmetry score for which scores greater than $50 \%$ indicated a preference or accurate detection for symmetry and scores less than $50 \%$ scores indicated a preference for asymmetry or inaccurate detection for symmetry.

To assess overall preferences for symmetry, one-sample t-tests against chance preference $(50 \%$, equal selection of symmetric and asymmetric versions) were conducted split by participant age group. For the adult group, these revealed significant preferences for symmetric human female $\left(\mathrm{t}_{62}=7.50, p<0.001\right)$ and male faces $\left(\mathrm{t}_{62}=6.85, p<0.001\right)$ and for symmetric macaque female $\left(\mathrm{t}_{62}=2.07, p=0.043\right)$ and male $\left(\mathrm{t}_{62}=4.25, p<0.001\right)$ faces. For the children group, these revealed no significant preferences for symmetric human female $\left(\mathrm{t}_{44}=1.18, p=0.244\right)$ and male faces $\left(\mathrm{t}_{44}=1.13, p=0.264\right)$ and for symmetric macaque female $\left(\mathrm{t}_{44}=1.57, p=0.123\right)$ and male $\left(\mathrm{t}_{44}=0.35, p=0.731\right)$ faces. Scores can be seen in Figure 2.

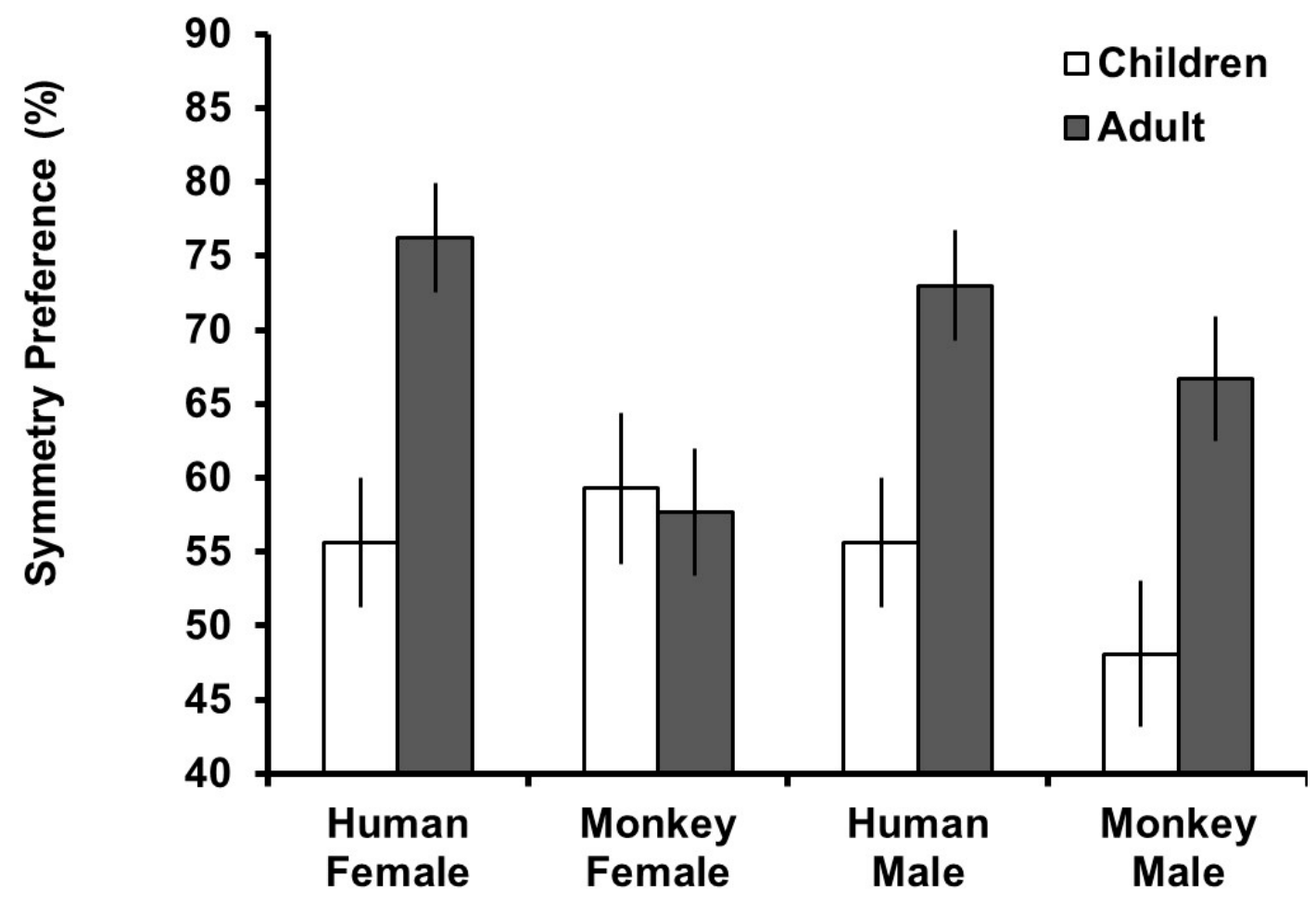

Figure 2. Preferences for symmetric vs. asymmetric images across different stimulus types by age group (+/- 1SEM). Scores greater than $50 \%$ indicated that symmetric versions were preferred over asymmetric versions.

To assess overall detection accuracy for symmetry, one-sample t-tests against chance detection (50\%, equal selection of symmetric and asymmetric versions) were conducted split by participant 
age group. For the adult group, these revealed significant detection for symmetric human female $\left(\mathrm{t}_{62}=15.92, p<0.001\right)$ and male faces $\left(\mathrm{t}_{62}=11.78, p<0.001\right)$ and for symmetric macaque female $\left(t_{62}=17.56, p<0.001\right)$ and male $\left(t_{62}=9.17, p<0.001\right)$ faces. For the children group, these revealed significant detection for symmetric human female $\left(\mathrm{t}_{44}=4.18, p<0.001\right)$ but not male faces $\left(\mathrm{t}_{44}=1.20\right.$, $p=0.237)$ and significant detection for symmetric macaque female $\left(t_{44}=3.46, p=0.001\right)$ and male $\left(t_{44}=5.60, p<0.001\right)$ faces. Scores can be seen in Figure 3.

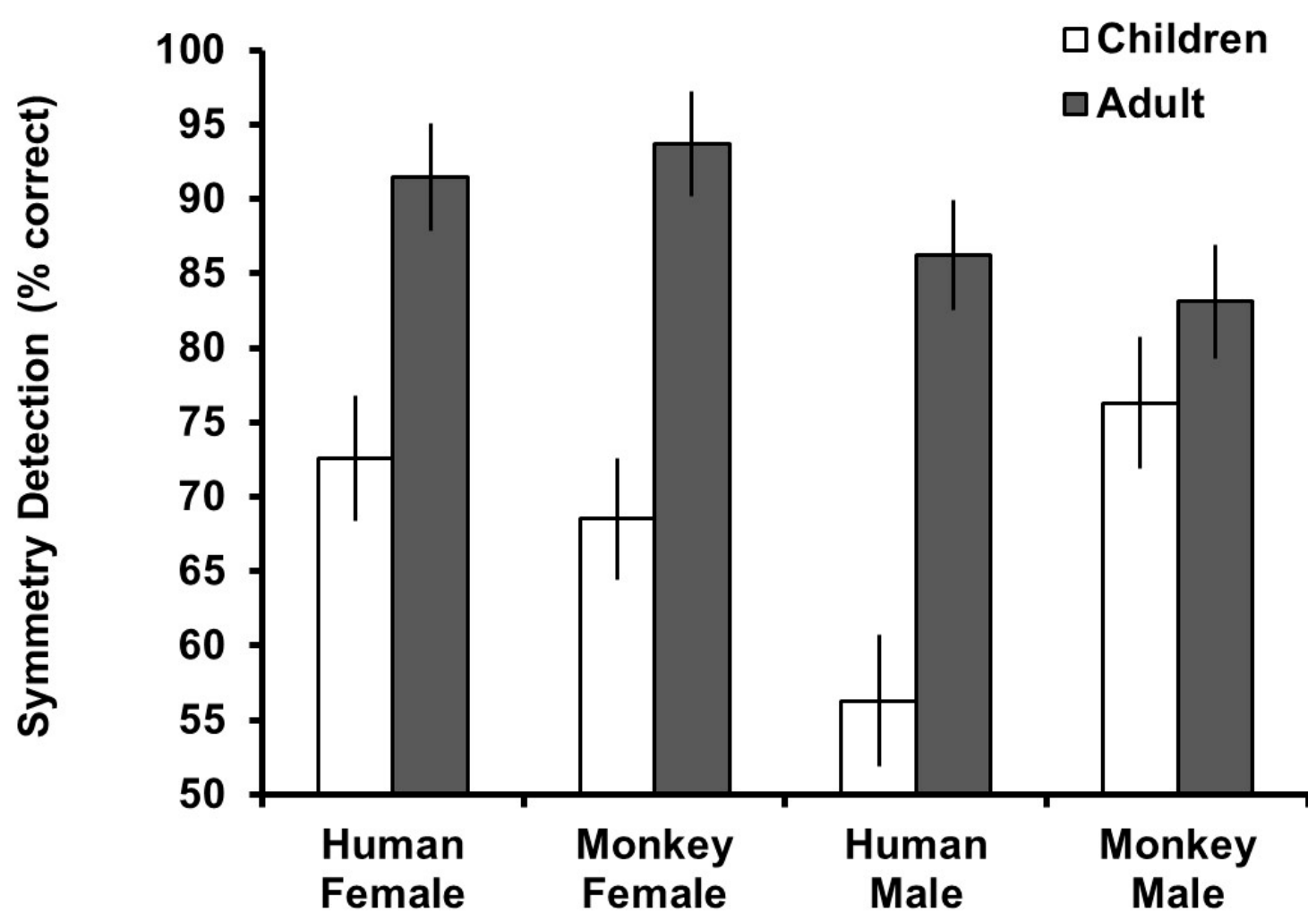

Figure 3. Accurate detection for symmetric vs. asymmetric images across different stimulus types by age group (+/- 1SEM). Scores greater than $50 \%$ indicated that symmetric versions were correctly identified as more symmetric.

To assess the effect of stimuli type on preferences for symmetry by age group, a mixed model ANOVA was conducted with preference for symmetry as the dependent variable, stimulus sex (female/male) and stimulus species (human/macaque) as within-participant factors, and age group as a between-participant factor. This revealed significant main effects of age group $\left(\mathrm{F}_{1,106}=13.22, p<0.001\right)$ and stimulus species $\left(\mathrm{F}_{1,106}=5.77, p=0.018\right)$, and a significant three-way interaction among age group, stimulus sex, and stimulus species $\left(\mathrm{F}_{1,106}=4.50, p=0.036\right)$. There was a non-significant interaction between age group and stimulus species $\left(\mathrm{F}_{1,106}=3.17, p=0.078\right)$. No other main effects or interactions were significant (all $\mathrm{F}<2.46$, all $p>0.120$ ). From Figure 2, the main effect of age group reflected generally higher preferences for symmetry in the adult group and the effect of stimulus species reflected higher preferences for symmetry in human stimuli. The three-way interaction reflected that the difference in preference between age groups was similar for human stimuli, but for monkey stimuli, adults and children had similar preferences for symmetry in female faces but children had lower preferences for male faces.

A mixed model ANOVA was conducted in the same way as above but with symmetry detection as the dependent variable to examine the effect of stimuli type on detection of symmetry by age group. This revealed significant main effects of age group $\left(\mathrm{F}_{1,106}=24.33, p<0.001\right)$, stimulus species $\left(\mathrm{F}_{1,106}=4.43\right.$, $p=0.038)$, and stimulus sex $\left(\mathrm{F}_{1,106}=6.06, p=0.015\right)$. There was a significant interaction between age 
group and stimulus species $\left(\mathrm{F}_{1,106}=5.78, p=0.018\right)$ and a significant interaction between stimulus sex and stimulus species $\left(\mathrm{F}_{1,106}=3.98, p=0.049\right)$. There was a significant three-way interaction among age group, stimulus sex, and stimulus species $\left(\mathrm{F}_{1,106}=9.72, p<0.001\right)$. There was no significant interaction between age group and stimulus species $\left(\mathrm{F}_{1,106}=0.55, p=0.460\right)$. From Figure 3 , the main effect of age group reflected generally higher detection of symmetry in the adult group. Other main effects and interactions were tied to the three-way interaction, which reflected that the difference in detection between age groups was similar for female stimuli, but for male stimuli, adults and children had more similar detection of symmetry in monkey faces but children had lower accuracy in detection for human faces.

\subsection{Preference Controlling for Detection}

To test if differences in preference by age group was linked to detection ability, one-way ANCOVAs were conducted for each stimuli type with preference as the dependent variable, age group as a between-subject factor, and the relevant detection score as covariate. For human female faces this revealed a significant effect of age group controlling for detection scores $\left(\mathrm{F}_{1,105}=8.38, p=0.005\right)$ and a non-significant effect of detection $\left(\mathrm{F}_{1,105}=3.02, p=0.085\right)$. For human male faces, this revealed a non-significant effect of age group controlling for detection scores $\left(\mathrm{F}_{1,105}=3.12, p=0.080\right)$ and a significant effect of detection $\left(\mathrm{F}_{1,105}=4.81, p=0.030\right)$. For monkey female faces, this revealed a non-significant effect of age group controlling for detection scores $\left(\mathrm{F}_{1,105}=0.14, p=0.705\right)$ and a non-significant effect of detection $\left(\mathrm{F}_{1,105}=0.14, p=0.709\right)$. For monkey male faces. this revealed a significant effect of age group controlling for detection scores $\left(\mathrm{F}_{1,105}=7.49, \mathrm{p}=0.007\right)$ and a non-significant effect of detection $\left(\mathrm{F}_{1,105}=0.80, \mathrm{p}=0.373\right)$.

\subsection{Preference and Detection Correlations}

To assess the relationship between symmetry preferences and detection, Pearson product moment correlations were performed, split by group. For adults, these revealed non-significant relationships between detection and preference for human female $(\mathrm{r}=0.08, p=0.532)$, human male $(\mathrm{r}=0.25$, $p=0.052)$, monkey female $(\mathrm{r}=0.18, p=0.163)$, and monkey male $(\mathrm{r}=0.12, p=0.346)$ faces. For children, these revealed non-significant relationships between detection and preference for human female $(\mathrm{r}=0.24, p=0.120)$, human male $(\mathrm{r}=0.18, p=0.233)$, monkey female $(\mathrm{r}=-0.04, p=0.777)$, and monkey male $(r=0.05, p=0.746)$ faces.

\subsection{Other Correlations}

To assess the relationships among symmetry preferences/detection across the four stimulus types, Pearson product moment correlations were performed, split by group. For adults, preferences for symmetry were significantly positively correlated for human male and female faces $(\mathrm{r}=0.35, p=0.005)$, monkey male and female faces $(r=.39, p=.002)$, human female and monkey female faces $(r=0.26$, $p=0.039)$, and human male and monkey male faces $(\mathrm{r}=0.32, p=0.010)$. There were positive but not significant correlations for human male and female monkey faces $(\mathrm{r}=0.23, p=0.066)$ and human female and monkey male faces $(r=0.19, p=0.142)$. For children, preferences were not significantly correlated for any face types (all $\mathrm{r}$ between -0.05 and 0.18 , and $p>0.216$ ).

For adults, there were significant correlations for detection of symmetry in all face types (all $\mathrm{r}$ between 0.47 and 0.79 , and $p<0.001$ ). For children, there was a positive significant relationship for human male and monkey male faces $(r=0.39, p=0.008)$. There were positive but not significant correlations for human female and monkey female faces $(\mathrm{r}=0.26, p=0.081)$, human male and female monkey faces $(r=0.28, p=0.068)$, human female and monkey male faces $(r=0.26, p=0.086)$, monkey male and female faces $(\mathrm{r}=0.08, p=0.582)$, and human male and female $(\mathrm{r}=0.04, p=0.798)$. 


\subsection{Linear Effects of Age within Age Group}

Pearson product moment correlations were conducted to examine relationships with age within age group. For adults, age was not significantly related to preferences or detection ability in any face type. The strongest correlation was with preferences for symmetry in human female faces $(r=-0.24$, $p=0.063$, all other $\mathrm{r}$ ranged from -0.20 to 0.03 , all $p>0.132$ ). For children, age was significantly related to detection of female monkey symmetry $(\mathrm{r}=0.41, p=0.005)$ but not significantly related to preferences for or detection of symmetry in any other face type (all $\mathrm{r}$ ranged from -0.22 to 0.09 , all $p>0.172$ ).

\section{Discussion}

This study demonstrated that symmetry preference and detection varied according to the type of stimuli being judged and between the children and adult age groups. Preference and detection of symmetry was highest for the adult group, with preference for symmetry higher for human than monkey faces in adults. In the adult group, detection was higher for female faces of both species than male faces, while the pattern was mixed for children. The correlations between preferences for symmetry and its detection were generally positive but low (highest $r=0.25$ ). The dissociation between preference and detection can be seen in adults judging female monkey faces, for which detection of symmetry was highest of all stimuli but preference for symmetry was lowest. The dissociation can also be seen in the children group where detection of symmetry was highest for monkey male faces, but preference was lowest.

Significant preferences for symmetry in human face stimuli for adult observers is consistent with previous work using manipulated stimuli $[8,9,21,49]$. The finding that symmetry preferences in adults were stronger for human than for monkey faces is also consistent with a previous study showing that symmetry was preferred more in human faces than in monkey faces and abstract art images [39]. Other studies have shown that symmetry is preferred more in salient biological images than in more abstract visual stimuli [36,50], and the results here suggest species can impact preference within the broad category of biological stimuli. Preferences across stimuli were intercorrelated for adults, but the correlations were generally low (the highest for human male and female faces was $r=0.35$ ). This is consistent with previous work showing limited correlations between symmetry preferences for human faces and more abstract stimuli [36]. Taken together, the results here do not generally a support a simple perceptual bias view of symmetry preference that posits preference is a basic process of the perceptual system [22-24]. Such a view would predict that symmetry preferences would be similar across stimuli types that vary in symmetry in the same way and that preferences for symmetry across stimuli would be similar within each observer (i.e., if each observers' preference for symmetry was generated via a basic process, we would expect that process to apply in a similar way across stimuli).

Children did not show significant preferences for symmetry in this study. From a simple perceptual bias view this is surprising as the basic processes of perception should be the same between children and adults. Experience could play a role in the difference as adults have been exposed to more faces than children; however, it seems likely that they will have been exposed to very large number faces by age 8 and this would be likely enough to generate a symmetric internal prototype if that explained preferences for symmetry [21,27-30]. Preferences for face symmetry is seen when controlling for rated distinctiveness [8], again suggesting that attraction to symmetry is at least partially independent of an individual's representation of the prototypical face. Given there were also no linear effect between detection and age within the adult sample, greater experience appears an unlikely reason for the difference. Motivation is an alternative explanation, with adult men being more interested in symmetry associated with some aspect of mate quality than male children. While this would be consistent with an evolutionary advantage view for human female faces, it is difficult to apply to preferences for male and monkey faces, which are not relevant for heterosexual male mate preferences. Neither experience or mating motivation appear to explain the pattern of difference between preferences for symmetry in adults and children. Future work can usefully test changes across puberty or across time in younger children to examine mating motivation and experience effects on symmetry preferences. 
There was significant detection of symmetry across stimuli for both adults and children, with higher accuracy in the adults. The pattern of detection did not follow the pattern for preference for either adults or children. In adults, preferences were highest for human faces but for detection preferences were highest for female faces, irrespective of species. In children, detection was highest for monkey male faces while preference was lowest for this stimulus type. It is unclear why detection ability varied across both species and sex in both adults and children. That children were better at detecting symmetry in monkey male than human male faces is surprising and suggestive that experience with a stimuli type does not underpin symmetry detection as, if experience were important, we would expect detection to be higher for stimuli with which observers have more experience. The same transforms were applied to human and monkey faces, keeping variation in asymmetry similar. Differences in judging these stimuli are then not dependent on asymmetry present and reflect some other aspect of processing by the observer. Future work can further examine how detection ability varies both with age and different types of stimuli.

Children had lower preferences and lower accuracy in detection of symmetry than adults, and it is possible poor detection explains the lack of preference in children. Controlling for detection, however, a significant difference in preference between adults and children was still seen. This indicates that differences in preference between children and adults is not completely dependent on detection ability. Further, weak correlations between preference and detection also support the idea that this ability does not underpin symmetry preferences. Similarly, the pattern of means for detection and preference noted above suggest the two measures can be decoupled. Overall, results here support previous findings [49] suggesting a dissociation between symmetry preference and detection, but contrast with other studies suggesting preferences can be explained by detection ability [10]. More research is needed to examine the circumstances under which detection and preference are more or less related. For example, it is possible greater deviations in symmetry may lead to a stronger relationship between preference and detection and that, with small deviations, different processes for the two judgments lead to different generated responses.

Overall, the results of this study reveal a complex pattern of preferences across type of stimuli and age group. These preferences appear decoupled from detection ability. The results from adults partially support predictions of an evolutionary advantage view because preferences were higher for human faces than monkey, and marginally higher for human female faces than male faces. This is consistent with ideas that symmetry may be used as a guide to mate quality, e.g., [21,31,32] or general partnerships (including male-male friendship). Higher preferences for symmetry in adults, for who these partnerships are more relevant, than for children is also consistent with the evolutionary view. Indeed, perceptions of health appear to be important in attraction to symmetric human faces $[7,51]$. The evolutionary view, however, does not explain why symmetry preferences are also higher in adults for monkey faces than in children. The results do not support the idea that simple perceptual bias views explain all of symmetry preference. Previous studies present findings that are difficult to account for, such as symmetry preferences being higher for opposite-sex compared to same-sex faces [33-35], also seen in the adult sample here. These results only suggest that the perceptual bias view may not fully account for symmetry preferences and some of symmetry preference could be due to perceptual bias. Indeed, multiple mechanisms may determine symmetry preference that include basic visual system processes and higher order motivational processes acting together. The motivational processes may drive differences in preferences between stimuli types [21,49].

\section{Conclusions}

In conclusion, this study demonstrated that both age of observer and stimuli type matter in symmetry preferences. Older observers generally had higher preferences for symmetry but preferred symmetry most in human vs monkey stimuli. Across both age groups, symmetry preferences and detection abilities were weakly related suggesting that symmetry preference is not underpinned by detection abilities. Both age group differences and stimuli-based differences could reflect motivational 
influences on preferences for symmetry. In this way, the study supports some ideas from an evolutionary advantage view of symmetry preference, which may occur alongside symmetry preference generated by perceptual biases.

Author Contributions: Conceptualization, A.C.L. and J.A.F.G.; methodology and data collection, A.C.L. and J.A.F.G.; analysis, A.C.L.; investigation, A.C.L. and J.A.F.G.; resources, A.C.L.; data curation, A.C.L.; writing—original draft preparation, A.C.L.; writing—review and editing A.C.L. and J.A.F.G., All authors have read and agreed to the published version of the manuscript.

Funding: Anthony Little was supported by a Royal Society University Research Fellowship during data collection. Acknowledgments: We express our great thanks to Corri Waitt who collected the macaque monkey images.

Conflicts of Interest: The authors declare no conflict of interest. The funders had no role in the design of the study; in the collection, analyses, or interpretation of data; in the writing of the manuscript, or in the decision to publish the results.

\section{References}

1. Tinio, P.P.L.; Leder, H. Just how stable are stable aesthetic features? Symmetry, complexity, and the jaws of massive familiarization. Acta Psychol. 2009, 130, 241-250. [CrossRef] [PubMed]

2. Gartus, A.; Leder, H. The small step toward asymmetry: Aesthetic judgment of broken symmetries. I Percept. 2013, 4, 361-364. [CrossRef] [PubMed]

3. Grammer, K.; Thornhill, R. Human (Homo sapiens) facial attractiveness and sexual selection: The role of symmetry and averageness. J. Comp. Psychol. 1994, 108, 233-242. [CrossRef] [PubMed]

4. Mealey, L.; Bridgestock, R.; Townsend, G. Symmetry and perceived facial attractiveness. J. Pers. Soc. Psychol. 1999, 76, 151-158. [CrossRef] [PubMed]

5. Scheib, J.E.; Gangestad, S.W.; Thornhill, R. Facial attractiveness, symmetry, and cues to good genes. Proc. R. Soc. Lond. B. Biol. Sci. 1999, 266, 1913-1917. [CrossRef] [PubMed]

6. Jones, B.C.; Little, A.C.; Burt, D.M.; Perrett, D.I. When facial attractiveness is only skin deep. Perception 2004, 33, 569-576. [CrossRef] [PubMed]

7. Jones, B.C.; Little, A.C.; Penton-Voak, I.S.; Tiddeman, B.P.; Burt, D.M.; Perrett, D.I. Facial symmetry and judgements of apparent health-Support for a "good genes" explanation of the attractiveness-symmetry relationship. Evol. Hum. Behav. 2001, 22, 417-429. [CrossRef]

8. Rhodes, G.; Proffitt, F.; Grady, J.; Sumich, A. Facial symmetry and the perception of beauty. Psychon. Bull. Rev. 1998, 5, 659-669. [CrossRef]

9. Perrett, D.I.; Burt, D.M.; Penton-Voak, I.S.; Lee, K.J.; Rowland, D.A.; Edwards, R. Symmetry and human facial attractiveness. Evol. Hum. Behav. 1999, 20, 295-307. [CrossRef]

10. Lewis, M.B. Fertility affects asymmetry detection not symmetry preference in assessments of 3D facial attractiveness. Cognition 2017, 166, 130-138. [CrossRef]

11. Hughes, S.M.; Aung, T. Symmetry in Motion: Perception of Attractiveness Changes with Facial Movement. J. Nonverbal Behav. 2018, 42, 267-283. [CrossRef]

12. Soler, C.; Kekalainen, J.; Nunez, M.; Sancho, M.; Nunez, J.; Yaber, I.; Gutierrez, R. Male facial anthropometry and attractiveness. Perception 2012, 41, 1234-1245. [CrossRef] [PubMed]

13. Kowner, R. Facial asymmetry and attractiveness judgment in developmental perspective. J. Exp. Psychol. Hum. Percept. Perform. 1996, 22, 662-675. [CrossRef] [PubMed]

14. Jones, A.L.; Jaeger, B. Biological Bases of Beauty Revisited: The Effect of Symmetry, Averageness, and Sexual Dimorphism on Female Facial Attractiveness. Symmetry 2019, 11. [CrossRef]

15. Kocnar, T.; Saribay, S.A.; Kleisner, K. Perceived attractiveness of Czech faces across 10 cultures: Associations with sexual shape dimorphism, averageness, fluctuating asymmetry, and eye color. PLoS ONE 2019, 14, e0225549. [CrossRef] [PubMed]

16. Van Dongen, S. Associations between asymmetry and human attractiveness: Possible direct effects of asymmetry and signatures of publication bias. Ann. Hum. Biol. 2011, 38, 317-323. [CrossRef]

17. Rhodes, G.; Yoshikawa, S.; Clark, A.; Lee, K.; McKay, R.; Akamatsu, S. Attractiveness of facial averageness and symmetry in non-Western populations: In search of biologically based standards of beauty. Perception 2001, 30, 611-625. 
18. Little, A.C.; Apicella, C.L.; Marlowe, F.W. Preferences for symmetry in human faces in two cultures: Data from the UK and the Hadza, an isolated group of hunter-gatherers. Proc. R. Soc. Lond. Ser. B Biol. Sci. 2007, 274, 3113-3117. [CrossRef]

19. Møller, A.P.; Thornhill, R. Bilateral symmetry and sexual selection: A meta-analysis. Am. Nat. 1998, 151, 174-192. [CrossRef]

20. Waitt, C.; Little, A.C. Preferences for symmetry in conspecific facial shape among Macaca mulatta. Int. J. Primatol. 2006, 27, 133-145.

21. Little, A.C.; Jones, B.C. Evidence against perceptual bias views for symmetry preferences in human faces. Proc. R. Soc. Lond. B. Biol. Sci. 2003, 270, 1759-1763. [CrossRef] [PubMed]

22. Attneave, F. Symmetry, information, and memory for patterns. Am. J. Psychol. 1955, 68, 209-222. [CrossRef] [PubMed]

23. Herbert, A.M.; Humphrey, G.K. Bilateral symmetry detection: Testing a 'callosal' hypothesis. Perception 1996, 25, 463-480. [CrossRef]

24. Mach, E. Contributions to the Analysis of the Sensations; Open Court: LaSalle, IL, USA, 1897.

25. Rensch, B. Vesuche uber menschliche Auslosermerkmale beider Geschlecter. Z. Morphol. Anthropol. 1963, 53, 139-164.

26. Gombrich, E.H. The Sense of Order: A Study in the Psychology of Decorative Art; Phaidon: London, UK, 1984.

27. Jansson, L.; Forkman, B.; Enquist, M. Experimental evidence of receiver bias for symmetry. Anim. Behav. 2002, 63, 617-621. [CrossRef]

28. Enquist, M.; Arak, A. Symmetry, Beauty and evolution. Nature 1994, 372, 169-172. [CrossRef]

29. Enquist, M.; Ghirlanda, S. The secrets of faces. Nature 1998, 394, 826-827.

30. Enquist, M.; Johnstone, R.A. Generalization and the evolution of symmetry preferences. Proc. R. Soc. Lond. Ser. B Biol. Sci. 1997, 264, 1345-1348. [CrossRef]

31. Thornhill, R.; Gangestad, S.W. Facial attractiveness. Trends Cognit. Sci. 1999, 3, 452-460. [CrossRef]

32. Wade, T.J. The Relationships between Symmetry and Attractiveness and Mating Relevant Decisions and Behavior: A Review. Symmetry 2010, 2, 1081-1098. [CrossRef]

33. Little, A.C.; Burt, D.M.; Penton-Voak, I.S.; Perrett, D.I. Self-perceived attractiveness influences human female preferences for sexual dimorphism and symmetry in male faces. Proc. R. Soc. Lond. Ser. B Biol. Sci. 2001, 268, 39-44. [CrossRef] [PubMed]

34. Penton-Voak, I.S.; Jones, B.C.; Little, A.C.; Baker, S.; Tiddeman, B.; Burt, D.M.; Perrett, D.I. Symmetry, sexual dimorphism in facial proportions, and male facial attractiveness. Proc. R. Soc. Lond. Ser. B Biol. Sci. 2001, 268, 1617-1623. [CrossRef] [PubMed]

35. Little, A.C.; Jones, B.C.; DeBruine, L.M.; Feinberg, D.R. Symmetry and sexual dimorphism in human faces: Interrelated preferences suggest both signal quality. Behav. Ecol. 2008, 19, 902-908. [CrossRef]

36. Young, S.G.; Sacco, D.F.; Hugenberg, K. Vulnerability to disease is associated with a domain-specific preference for symmetrical faces relative to symmetrical non-face stimuli. Eur. J. Soc. Psychol. 2011, 41, 558-563. [CrossRef]

37. Little, A.C.; Jones, B.C.; DeBruine, L.M. Exposure to visual cues of pathogen contagion changes preferences for masculinity and symmetry in opposite-sex faces. Proc. R. Soc. Lond. Ser. B Biol. Sci. 2011, 278, 2032-2039. [CrossRef]

38. Bertamini, M.; Rampone, G.; Makin, A.D.J.; Jessop, A. Symmetry preference in shapes, faces, flowers and landscapes. PeerJ 2019, 7. [CrossRef]

39. Little, A.C. Domain specificity in human symmetry preferences: Symmetry is most pleasant when looking at human faces. Symmetry 2014, 6, 222-233. [CrossRef]

40. Radlova, S.; Landova, E.; Frynta, D. Judging Others by Your Own Standards: Attractiveness of Primate Faces as Seen by Human Respondents. Front. Psychol. 2018, 9. [CrossRef]

41. Damon, F.; Li, Z.H.; Yan, Y.; Li, W.; Guo, K.; Quinn, P.C.; Pascalis, O.; Meary, D. Preference for Attractive Faces Is Species-Specific. J. Comp. Psychol. 2019, 133, 262-271. [CrossRef]

42. Leder, H.; Tinio, P.P.L.; Brieber, D.; Kroner, T.; Jacobsen, T.; Rosenberg, R. Symmetry Is Not a Universal Law of Beauty. Empir. Stud. Arts 2019, 37, 104-114. [CrossRef]

43. Weichselbaum, H.; Leder, H.; Ansorge, U. Implicit and Explicit Evaluation of Visual Symmetry as a Function of Art Expertise. I Percept. 2018, 9. [CrossRef] [PubMed] 
44. Little, A.C.; Saxton, T.K.; Roberts, S.C.; Jones, B.C.; DeBruine, L.M.; Vukovic, J.; Perrett, D.I.; Feinberg, D.R.; Chenore, T. Women's preferences for masculinity in male faces are highest during reproductive age range and lower around puberty and post-menopause. Psychoneuroendocrinology 2010, 35, 912-920. [CrossRef]

45. Little, A.C.; Jones, B.C.; Waitt, C.; Tiddeman, B.P.; Feinberg, D.R.; Perrett, D.I.; Apicella, C.L.; Marlowe, F.W. Symmetry is related to sexual dimorphism in faces: data across culture and species. PLOS ONE 2008, 3, e2106. [CrossRef] [PubMed]

46. Little, A.C.; Hancock, P.J. The role of masculinity and distinctiveness on the perception of attractiveness in human male faces. Br. J. Psychol. 2002, 93, 451-464. [CrossRef] [PubMed]

47. Benson, P.J.; Perrett, D.I. Extracting prototypical facial images from exemplars. Perception 1993, 22, $257-262$. [CrossRef]

48. Tiddeman, B.P.; Burt, D.M.; Perrett, D.I. Prototyping and transforming facial texture for perception research. IEEE Comput. Graph. 2001, 21, 42-50. [CrossRef]

49. Little, A.C.; Jones, B.C. Attraction independent of detection suggests special mechanisms for symmetry preferences in human face perception. Proc. R. Soc. Lond. Ser. B Biol. Sci. 2006, 273, 3093-3099. [CrossRef]

50. Evans, C.S.; Wenderoth, P.; Cheng, K. Detection of bilateral symmetry in complex biological images. Perception 2000, 29, 31-42. [CrossRef]

51. Rhodes, G.; Yoshikawa, S.; Palermo, R.; Simmons, L.W.; Peters, M.; Lee, K.; Halberstadt, J.; Crawford, J.R. Perceived health contributes to the attractiveness of facial symmetry, averageness, and sexual dimorphism. Perception 2007, 36, 1244-1252. [CrossRef]

Publisher's Note: MDPI stays neutral with regard to jurisdictional claims in published maps and institutional affiliations.

(C) 2020 by the authors. Licensee MDPI, Basel, Switzerland. This article is an open access article distributed under the terms and conditions of the Creative Commons Attribution (CC BY) license (http://creativecommons.org/licenses/by/4.0/). 